\title{
VARIAÇÕES ESTÉTICAS E POLÍTICAS SOBRE UM PENSAMENTO NÃO-REPRESENTATIVO
}

\author{
André Vinícius Nascimento Araújo ${ }^{1}$
}

\begin{abstract}
Resumo: As representações conformam-nos a certos modos de ver, de sentir e de enunciar que são perspectivas fechadas de nossas experiências estéticas e políticas. Sendo assim, se elas tornam restritas as nossas maneiras de se relacionar com os acontecimentos, é possível pensar para além das representações? Colocamos tal questão no horizonte da leitura de pensadores como Friedrich Nietzsche, Gilles Deleuze, Michel Foucault e Jacques Rancière. Porém, nosso foco incide sobre a crítica ao paradigma representativo, apresentada em alguns momentos distintos da obra de Deleuze, inclusive daquela que escreve junto com Félix Guattari, quando trata da questão da rostidade. Pretendemos, primeiramente, abordar aquele que para Nietzsche não é senão o maior de todos os acontecimentos a se dar na existência humana: a morte de Deus. Acontecimento que implica uma cisão nos modos tradicionais de pensar, subsumidos a representações morais e metafísicas da existência. De que maneira a morte de Deus será o horizonte de sentido para um modo de pensar, tanto em Deleuze, quanto em Foucault, que considera as coisas e as representações que fazemos delas, como interpretações de um certo jogo de forças e de subjetivação? Por último, poderemos avaliar a partir do conceito rancièriano de partilha do sensivel, como encontramos em Deleuze uma prática do pensamento que busca escapar de uma distribuição sedentária do sensível e do político quando este se restringe ao paradigma das representações.

Palavras-chave: acontecimento - rostidade - modernidade estética - subjetividade.
\end{abstract}

\section{INTRODUÇÃO: IDENTIDADE E REPRESENTAÇÃO HEGEMÔNICA}

Nos dias atuais, vemos constantemente na produção desenfreada de enunciados do campo político a presença de termos como "representação" e "identidade". E não somente no âmbito de lutas micropolíticas, mas, como elemento de uma prática discursiva macropolítica que busca ganhar espaço no interior das instituições sociais, educacionais e culturais.

\footnotetext{
${ }^{1}$ Doutorando no Programa de Pós Graduação em Filosofia (PPGFIL) pela Universidade Federal do Rio Grande do Norte (UFRN), atuando na linha de pesquisa em Crítica da Metafísica. Bolsista CAPES. E-mail: andrenascimento07@yahoo.com.br. Orientador: Dr. Eduardo Aníbal Pellejero.
} 
Há grupos que lutam pelo direito ou reconhecimento de identidades que lhes são negadas pelas representações hegemônicas do tipo macho-branco-europeu-heterossexual. Há outros que produzem formas dissidentes de pôr em questão não somente as representações e identidades hegemônicas, como as próprias noções de identidade e representação.

Se as representações hegemônicas parecem formar uma única identidade no singular, dominante sob a própria cultura e linguagem em que estamos de modo geral inseridos, as identidades que aparecem como "subalternas" são múltiplas e há até mesmo aqueles que não reclamam para si uma identidade, ou que reclamam no território de seus próprios corpos muitas delas.

Longe de querer dar conta de toda a complexidade desses processos de subjetivação política, nosso intuito é bem mais modesto e não menos problemático. Queremos discutir um paradigma estético do pensamento que não pensa mais sob o modelo da representação e subsequentemente da identidade. Então, a partir desse outro modo de pensamento, poderemos retomar o caminho por onde iniciamos.

\section{UM ACONTECIMENTO GRANDE DEMAIS PARA SE PENSAR: A MORTE DE DEUS E SUAS IMPLICAÇÕES}

Friedrich Nietzsche é comumente lembrado na história da filosofia como um momento de ruptura no modo tradicional de pensar europeu-ocidental. E poderíamos dizer sem hesitar que muito disso se deve ao tom dramático que ele confere a um acontecimento decisivo ao destino do homem europeu e de sua cultura. E que grande acontecimento seria esse? A morte de Deus.

Ela é anunciada desde o primeiro aforismo do terceiro livro da Gaia Ciência, o aforismo 108, nas seguintes palavras: "Deus está morto; mas, tal como são os homens, durante séculos ainda haverá cavernas em que sua sombra será mostrada"2. Quem matou Deus? Quais as consequências deste ato? Que sombras são essas que desfilam nas cavernas onde estaríamos encerrados?

É no aforismo 125 do mesmo livro que um "homem louco" anunciará o assassino: o próprio homem. E deixará uma importante questão para seu tempo e para o porvir: "A grandeza desse ato não é demasiado grande para nós?”3. Justamente por ser tão grande esse ato, na impossibilidade de digeri-lo - esse cadáver sagrado - é que permanecemos imersos nas sombras da caverna. E o que seriam essas sombras senão aquilo que podemos chamar de "representações"?

Deus é o nome do fiador do "eu" e de suas representações (supostamente, por vezes tidas como "inatas"). Para utilizar os termos nietzschianos, sem esse fiador nossas formas de significar o mundo não passam de "antropomorfismos estéticos". Se matamos Deus com o poder de domínio de nossa ciência sobre a natureza, descobrimos que as categorias provenientes da metafísica - das quais amplamente se serve a ciência - dizem menos sobre

\footnotetext{
2 NIETZSCHE, A Gaia Ciência, aforismo 108.

${ }^{3}$ NIETZSCHE, A Gaia Ciência, aforismo 125.
} 
o que as coisas são, e mais sobre nossa forma de ordenar discursos e práticas. Essas categorias não são mais do que "artigos de fé" ciclo etc.; a ordem representativa do conhecimento se desfaz como atributo de uma realidade para entrar na longa história de nossas ficções teóricas, políticas, literárias, religiosas.

Além da descoberta, com a constatação desse evento funesto, do nosso potencial inventivo, descobrimos a grandiosidade do "acontecimento" enquanto dimensão da existência irredutível às nossas ordens representativas.

A filosofia de Gilles Deleuze redescobre esse acontecimento como horizonte de sua tentativa de pensar a diferença. Em Diferença e repetição (1968), ele entende a morte de Deus como a "falência da representação" no mundo moderno, e diz no prólogo que este "é o [mundo] dos simulacros. Nele, o homem não sobrevive a Deus, nem a identidade do sujeito sobrevive à identidade da substância". Dito de outro modo, o "eu" ou o "cogito", considerado enquanto "alma” ou substância pensante, tida como primária em relação ao corpo, só poderia ser assegurada por um Deus enquanto inteligência imaterial que ordenaria mundo e alma.

Se não há Deus nessas condições, portanto, não há “identidades" enquanto compreendidas como verdades fundantes e permanentes de nossas representações. As identidades seriam "apenas "simuladas", produzidas como um "efeito" ótico por um jogo mais profundo, que é o da diferença e repetição"6.

$\mathrm{Na}$ obra subsequente a Diferença e repetição, Lógica do sentido (1969), esse mundo - no qual as representações e as identidades não são mais do que um jogo de diferença e repetição - é pensado em termos de acontecimento. Não se trata mais de pensar em termos de uma consciência e suas representações, mas de pensar através de signos que subsistem dos encontros entre os corpos.

Os encontros que vivemos na imanência de nossas vidas produziriam, desse outro ponto de vista (não representativo), uma instância problemática: o sentido. Aquilo que nos acontece no mundo não carrega em si uma significação dada, mas implica um sentido problemático, uma ideia a se pensar que remete a um signo irredutível a qualquer palavra que utilizemos para nomear o acontecimento que o suscitou.

Não há nenhum misticismo nessa sugestão de que os acontecimentos são irredutíveis às palavras, tampouco, nada neles se vela ou desvela, há uma proliferação indefinida de sentidos tão somente, a cada vez mais complexa, na qual o pensamento tenta compreender a multiplicidade de um encontro. $\mathrm{O}$ acontecimento torna indissociáveis, estética, ética, política e ontologia, enquanto instâncias de um pensamento não conformado. Um pensamento não de "causas" e "identidades", mas de "efeitos" e "perspectivas".

Um acontecimento político, por exemplo, uma revolução, não traz em si uma chave de leitura. Sobre ele multiplicam-se as narrativas: a do jornalista de direita, a do jornalista de esquerda, a de uma vedete de televisão etc. Mas nenhuma dessas vozes que se pretenda ser "representação dos fatos" compreende as possibilidades inesgotáveis dos acontecimentos. Tanto quanto, o momento de maior repressão, por vezes, pode ser aquele que suscita as maiores resistências.

\footnotetext{
${ }^{4}$ NIETZSCHE, A Gaia Ciência, aforismo 110.

${ }^{5}$ DELEUZE, Diferença e repetição, p. 15.

${ }^{6}$ DELEUZE, Diferença e repetição, p. 15.
} 
Nessa lógica do sentido, as representações não nos informam mais do que os "estados de coisas": o que nós e as nossas coisas temos sido em um determinado momento histórico. Mas, o acontecimento não se reduz nem se deixa deduzir das representações ou dos estados de coisa, nem sequer da história, que é a ordem da representação do homem branco, europeu, heterossexual, colonizador. O que o acontecimento contém são as possibilidades de outros possíveis, de recolocar em questão práticas e discursos; como o era com a morte de Deus: grande demais para ser pensada, tanto que preferiríamos acreditar na verdade de sombras que descobríamos ser capazes de representar nas paredes de nossas cavernas. Afinal não é tão fácil que a ordem vigente seja posta novamente em questão pelo acontecimento sem que se produzam nos espaços políticos as reações mais violentas.

Podemos aproximar também desse horizonte aberto pela morte de Deus - horizonte de um paradigma não representativo do pensamento - a obra As palavras e as coisas (1966) de Michel Foucault. O próprio título já o indica: não há nada mais do que práticas discursivas, em dado contexto, definindo contingencialmente certas relações entre palavras e coisas por elas denominadas.

Chamamos atenção, nesta obra, para o capítulo IX, intitulado "O homem e seus duplos", no qual, Foucault ${ }^{7}$ constata na passagem do "classicismo para a modernidade" uma ruptura na rede de representações do pensamento clássico. Tal ruptura provoca o que ele chama de "dispersão da linguagem", na qual "o ato de escrever" se fecha no interior das próprias palavras, ao invés de ordenar e classificar as coisas. O caso, por exemplo, da filologia que passa a perceber ao longo da história "palavras" que aparecem e desaparecem da ordem do discurso, e com elas desaparecem também as "coisas" tais como eram por aquelas designadas.

Uma vez que Foucault constata essa ruptura na ordem da representação na filologia, não será à toa que ainda no mesmo capítulo Nietzsche ganhará uma importância fundamental. O filólogo e filósofo de Basiléia será apontado como aquele no século XX que é "o primeiro a aproximar a tarefa filosófica de uma reflexão radical sobre a linguagem"

Mas a que ponto será levada tal reflexão? A um ponto onde o sujeito que fala no discurso corre o risco de "desaparecer". Foucault propõe um dialogo entre Nietzsche e o poeta Stéphane Mallarmé em torno dessa questão descoberta nos limites da reflexão sobre a linguagem, a partir da questão: quem fala? Sendo, então, Mallarmé aquele que em sua poesia faz desaparecer o sujeito, deixando-nos signos que se oferecem como enigmas que sequer podem compor uma cena imaginável em sua totalidade. Nesse sentido, poesia que não "representa" ou "significa" nada, contudo, insinua coisas e faz falar o silêncio.

Nesse momento de seu texto, Foucault põe uma questão na qual, assim como Deleuze, se insere no horizonte da "morte de Deus":

esse pensamento que fala desde milênios sem saber o que é falar, nem mesmo que ele fala - vai recuperar-se por inteiro e iluminar-se de novo no fulgor do ser? Não é isso o que Nietzsche preparava quando, no interior da linguagem, matava o homem e Deus ao mesmo tempo e assim prometia, com o [eterno] Retorno, o cintilar

${ }^{7}$ FOUCAULT, As palavras e as coisas, p. 418.
${ }^{8}$ FOUCAULT, As palavras e as coisas, p. 419. 
múltiplo e recomeçado dos deuses? Ou será preciso admitir, muito simplesmente, que tantas questões sobre a linguagem não fazem mais que prosseguir e no máximo concluir esse acontecimento, cuja existência e cujos primeiros efeitos desde o fim do século XVIII, a arqueologia nos ensinou?

Podemos a partir da densa questão de Foucault colocar uma outra: como é possível pensar para além da ordem representativa, uma vez que a partir da morte de Deus ela perde seu direito de soberania? A partir dessa questão, queremos retomar Diferença e repetição para pensar um outro paradigma do pensamento que para além da representação, descobre o simulacro como "ser do sensível", e para além da identidade, descobre as diferenças enquanto elementos irredutíveis dos acontecimentos.

\section{O PENSAMENTO E SUAS REPRESENTAÇÕES DOGMÁTICAS: CRÍTICA DA REPRESENTAÇÃO E MODERNIDADE ESTÉTICA EM DELEUZE}

Queremos chamar esse outro paradigma de "modernidade estética". Jacques Rancière, em $A$ partilha do sensivel, destaca na modernidade uma "transformação radical no paradigma representativo e nas suas implicações políticas" ${ }^{10}$. A ordem da representação - no sentido que Rancière a ela confere - é ao mesmo tempo estética e política, pois, se de um lado ela determina o que é visível e o que não é em dado contexto, por outro lado, ela distribui os lugares de autoridade, de identidade e direito a palavra.

Assim, a modernidade enquanto provoca uma ruptura na ordem representativa através de uma proliferação maciça de imagens e discursos, acabaria por implicar em outra distribuição dos lugares de cada quem no sensível e no político. Aparece, então, nesse horizonte, a ideia de uma "estética primeira", na qual as práticas artísticas intervêm diretamente sobre as práticas em geral da vida em comum ${ }^{11}$.

Essa noção de uma "partilha", ao mesmo tempo estética e política, permitirá a Rancière pensar regimes de identificação das práticas artísticas. No que diz respeito à modernidade não-representativa que nos interessa, ela será chamada de "regime estético das artes".

Em outro regime, o regime poético - sob um paradigma da representação ou da mímesis no sentido aristotélico - a arte só poderia ser idealizada e realizada sob "formas de normatividade que definem as condições segundo as quais as imitações podem ser reconhecidas como pertencendo propriamente a uma arte e apreciadas, nos limites dessa arte,

\footnotetext{
${ }^{9}$ FOUCAULT, As palavras e as coisas, p. 421.

${ }^{10}$ RANCIÈRE, A partilha do sensivel, p. 20.

${ }^{11}$ Quanto a essa intervenção das artes sobre a vida em comum, cito o próprio Rancière que diz ser "na interface criada entre 'suportes' diferentes, nos laços tecidos entre o poema e sua tipografia ou ilustração, entre o teatro e seus decoradores ou grafistas, entre o objeto decorativo e o poema, que se forma essa "novidade" que vai ligar o artista, que abole a figuração, ao revolucionário, inventor da vida nova” (RANCIÈRE, A partilha do sensivel, p. 23).
} 
como boas ou ruins, adequadas ou inadequadas" ${ }^{\prime 2}$. No regime estético, já não conta mais o critério normativo, mas, "um modo de ser sensível próprio aos produtos da arte"13.

Mas em que esse modo de ser sensível rompe com o paradigma da representação e faz da modernidade uma modernidade estética? Sem entrar na ampla significação que o regime estético tem no sentido de pôr em questão a própria noção de moderno e pósmoderno, podemos nos deter em dois de seus aspectos: o primeiro é a desobrigação da arte de regras, temas, gêneros etc., levando-a a uma autonomia tal que pode combinar estilos e entrar no espaço de outras práticas; o segundo, as "decisões de reinterpretação daquilo que a arte faz ou daquilo que a faz ser arte" ${ }^{14}$.

São alguns dos aspectos que encontramos em formas de artes modernas e contemporâneas e que estarão presentes no estilo filosófico de Deleuze. Nesse sentido, Rancière, em outro texto, reconhecerá Deleuze como um pensador da modernidade estética $^{15}$. Para ilustrar isto, basta que lembremos o prólogo de Diferença e repetição, no qual o filósofo propõe a "pesquisa de novos meios de expressão"16, interesse que mostra uma inspiração de estilo nietzschiana e um esforço paralelo ao de "renovação de estilo de outras

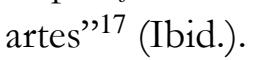

Deleuze reconhece na "arte moderna" um "teatro feito de metamorfoses e de permutações", de modo que, a "obra de arte abandona o domínio da representação para se tornar 'experiência', empirismo transcendental ou ciência do sensível"18. Conta nessa acepção, não tanto a legitimidade de um produto da arte, mas a experimentação que o envolve: experimentação que conduz de um lado ao ato de criação, e por outro lado à experimentação da própria arte sob outros regimes de pensamento. No empirismo transcendental, a estética tem papel central enquanto "disciplina apodítica" que nos põe em contato com o "ser do sensível", ou em outras palavras a diferença em seu estado intensivo e não-representativo.

Isso não significa que esse estado das diferenças se ofereça tão fácil ao pensamento. $\mathrm{Na}$ verdade, para Deleuze, não pensamos o tempo todo, justamente porque temos representações demais. Estamos sempre nos movendo em uma "imagem dogmática do pensamento" que nos dá pressupostos do que significa pensar. Tentemos resumir isso da seguinte maneira: o pensamento - segundo essa imagem - é naturalmente guiado por um bom senso e se dirige a um senso comum. Desse modo só posso saber o que "Todo mundo sabe", pensar por representações não passa de um contínuo exercício de "reconhecer" ou de "recognição", em uma distribuição sensível determinada pelas grandes instituições: o

12 RANCIÈRE, A partilha do sensivel, p. 31.

${ }^{13}$ RANCIÈRE, A partilha do sensivel, p. 32.

${ }^{14}$ RANCIÈRE, A partilha do sensivel, p. 36.

15 Trata-se do texto "Existe uma estética deleuziana?", apresentado por Jacques Rancière no Colóquio Gilles Deleuze de 1996, que está publicado em Gilles Deleuze: uma vida filosófica, 2000, p. 505-516. Rancière entende "os objetos e os modos de descrição e conceitualização de Deleuze" como vinculados ao que chama de "destino da estética" no sentido de um esforço tipicamente moderno de pensar um "sensível puro".

16 DELEUZE, Diferença e repetição, p. 18.

${ }^{17}$ DELEUZE, Diferença e repetição, p. 18.

18 DELEUZE, Diferença e repetição, p. 94. 
"Estado" e a "Igreja", por exemplo. Distribuição que Deleuze chamará de "sedentária" enquanto ela não passa de uma contínua reiteração de valores instituídos.

Por outro lado, só pensamos - e isso é um acontecimento muito raro na concepção deleuziana - quando somos forçados, violentados em nossas faculdades por uma potência impessoal. Justamente quando o acontecimento é grande demais para ser pensado, como dizíamos anteriormente, os valores e representações que nos asseguravam uma partilha fixa de identidades em nossos modos de sentir e viver já não dão conta de uma produção de singularidades e subjetividades. As diferenças só se mostram aí nesse momento em que não há fórmulas discursivas, em que temos que colocar questões, em que gaguejamos e temos de inventar conceitos que já não são mais "representações", senão signos que remetem as intensidades de um vivido que não se deixa capturar.

Mas essa violência na sensibilidade que se dá nos encontros compondo um acontecimento, por si só não produziria o pensamento. É preciso mesmo uma longa preparação que Deleuze chamará de "pedagogia dos sentidos"19. E nela, a obra de arte possui papel fundamental, pois, quem mais senão a obra de arte tem como uma de suas potencialidades desestabilizar as percepções ordinárias? Essa pedagogia seria possível enquanto "experimentação", trata-se de pôr as faculdades em jogo, desregrá-las de sua partilha sedentária do juízo determinante - falando em termos kantianos - e descobrir uma distribuição nômade das faculdades. Desviar nossos focos acomodados de atenção para desaprender o representado e só então aprender o que inventamos.

Toda obra de Deleuze parece mesmo atravessada por uma experimentação contínua. Se escreve comentários sobre outros filósofos, muito pouco os esclarece, senão que os rouba em uma zona de vizinhança que produz o conceito. E o mesmo se dá com as obras de arte, das quais extrai certas operações de pensamento. Exemplo disso é sua relação com o pintor Francis Bacon, descobrindo com ele uma "lógica da sensação".

A primeira coisa que sobressai desse encontro entre Deleuze e Francis Bacon é o esforço de ruptura com a representação na pintura. A representação aparece ao pintor como "figuração", principalmente o pintor moderno preso ao olhar das fotografias, do cinema e da televisão. Trata-se de clichês que povoam a tela em branco antes mesmo que ele inicie seu trabalho ${ }^{20}$. Para escapar da figuração, Bacon, conforme observa Deleuze, isola em seus quadros a "figura" em certas estruturas, de modo a impedir a formação de uma "narração" em conjunto com seus outros elementos.

O pintor se põe a desfazer os "dados figurativos", mas em tensão com a figuração que se impõe no ato de pintar, ao invés de seguir um caminho abstrato da "pura forma". Assim, além de isolar a figura, Bacon a distorce, como em seus autorretratos nos quais o rosto se desfaz ${ }^{21}$. Há uma série de figuras contorcidas nos quadros de Bacon que Deleuze compreende em termos de "histeria", no sentido de um corpo que desfaz seu organismo ${ }^{22}$. Mas o que é visado afinal por essa operação "histérica"? Atingir, sobretudo, um corpo intensivo ou em outros termos atingir a "sensação" revestida pelo excesso de figuração.

\footnotetext{
${ }^{19}$ DELEUZE, Diferença e repetição, p. 333.

${ }^{20}$ DELEUZE, Logique de la sensation, p. 83.

${ }^{21}$ DELEZUE, Logique de la sensation, p. 27.

22 DELEUZE, Logique de la sensation, p. 47.
} 
Trata-se ainda do "ser do sensível" ou "intensidade" anterior a qualquer representação, o "insensível" da sensibilidade que força a sentir, que em Logique de la sensation é colocado em termos de "forças". A pintura aqui, portanto, não "representa", não é "cópia de um modelo", ela pinta a sensação e as suas forças constituintes invisíveis ao corpo organizado.

\section{CONCLUSÃO: O QUE HÁ PARA ALÉM DE UM ROSTO?}

Mas em que sentido essa crítica estética da representação pode nos conduzir a um questionamento dos paradigmas políticos da subjetividade colocados em nossa introdução?

As representações não fazem parte apenas de um espaço fechado na linguagem e na abstração, elas se efetuam nos corpos, elas produzem dispositivos que capturam os corpos em ordens de significância, atuam de forma ativa no processo de constituição das subjetividades. Nesse sentido, ter uma identidade é ter um rosto, através do qual possamos ser reconhecidos pelos poderes constituídos.

Deleuze e Guattari, em Mil Platôs (1980), propõem analisar uma "máquina de rostidade" que não deixa de ser uma máquina abstrata, mas que atua como dispositivo concreto: tanto no sentido estético de traços como os da pintura ou da música (rostos em paisagens e em suas melodias), quanto no sentido político de uma seleção ou exclusão de certos tipos de rostos.

Um rosto não se reduz a cabeça, ele se sobrepõe a todo o corpo e mesmo a suas vestes ou gadgets. A uma rostidade corresponde sempre um modo significante de expressar, uma linguagem de um grupo ou tipo subjetivo: há um rosto de policial, um de mãe e outro de pai de família e assim por diante; nas palavras de Deleuze e Guattari: "uma língua cujos traços significantes são indexados nos traços de rostidade específicos"23.

Não obstante, há subjetividades e rostos dissidentes, cujos traços escapam da conformação da rostidade Homem-branco-Europeu que a ordem de representações dominantes tenta nos conformar. Rosto de negro ou rosto de travesti. Todos nós temos um rosto um pouco estranho - porque não se parece exatamente com as máquinas abstratas que o constitui - e por vezes a uns é até mesmo difícil olhá-lo no espelho, pois, sequer é possível reconhecer-se nele. E será mesmo que a questão é se reconhecer em um? O rosto que está aí não fomos nós que colocamos, na verdade "são os rostos que escolhem o sujeito" 24 , a máquina de rostidade é uma "produção social do rosto" 25.

Os "tiques" são um exemplo dado pelos autores desses movimentos nos quais os traços do rosto tentam escapar da violência de uma rostificação ordenadora. Nesse sentido, reivindicam que "o rosto é uma política" 26 e propõem para além de uma aventura de esteta, "desfazer o rosto". Mas como é possível desfazê-lo? O que há para além dele? Ou o que dá no mesmo, o que há para além da ordem das representações?

O que Deleuze e Guattari afirmam como "destino" político não se oferece como uma tarefa fácil. Por um lado, logo vamos nos apercebendo dos dispositivos de conformação,

\footnotetext{
${ }^{23}$ DELEUZE E GUATTARI, Mil platôs vol. 3, p. 29.

${ }^{24}$ DELEUZE E GUATTARI, Mil platôs vol. 3, p. 43.

${ }^{25}$ DELEUZE E GUATTARI, Mil platôs vol. 3, p. 45.

${ }^{26}$ DELEUZE E GUATTARI, Mil platôs vol. 3, p. 53.
} 
seleção e exclusão dos rostos. O racismo, por exemplo, determina as "variações de desvianças, em função do rosto Homem branco que pretende integrar em ondas cada vez mais excêntricas e retardadas os traços que não são conformes" ${ }^{\text {"27}}$; ou ainda ser cristianizado é ser rostificado: rosto do Cristo ou da Virgem Maria. Todos servem como "detectores de desvianças" e "ordenação de normalidades" 28 .

Desfazer esses rostos não é uma tarefa fácil, pois, nos termos de Deleuze e Guattari, ricocheteamos no "muro branco do significante" e caímos no "buraco negro da subjetividade". O risco da loucura ou da desintegração do corpo, ou ainda, da reterritorialização do rosto em uma nova identidade que nos conforme a ordem dominante. Nessa arriscada operação de arrebentar o muro, eles encontram na arte uma aliada, como atesta esta passagem:

Para isso [desfazer o rosto] são necessários, sem dúvida, todos os recursos da arte, e da mais elevada arte. É necessário toda uma linha de escrita, toda uma linha de picturalidade, toda uma linha de musicalidade... Pois é pela escrita que nos tornamos animais, é pela cor que nos tornamos imperceptíveis, é pela música que nos tornamos duros e sem recordação, ao mesmo tempo animal e imperceptível: amoroso ${ }^{29}$.

Para além das representações insinuam-se o que os autores vão chamar de devires. É nesse processo de "desfazer o rosto" que os acontecimentos se mostram, não como efetuados em estados de coisas permanentes, mas em um fluxo no qual a realidade dá lugar ao possível. Os devires são experienciados como formas distintas de sentir não humanas, pois o homem é precisamente o nome da ordem representativa remanescente da morte de Deus. Nesse sentido, não há “devir homem”, pois a rostidade já o tem como parâmetro. Há um devir-mulher, um devir-animal, um devir-imperceptível, e tantos outros a se descobrir do ponto de vista de uma experiência minoritária e transversal. Contudo, não há conformação possível a eles - como novos rostos e formas de ser reconhecido - porque neles o corpo descobre a potência de produzir continuamente outros modos de povoar o mundo.

Se no conceito de "rostidade" que encontramos em Mil platôs podemos visualizar ainda uma crítica da representação, com o conceito de "devires" que figura na mesma obra, o pensamento se abre a uma maneira mais ampla de conceber as diferenças que nos atravessam em relação àquela que aparecia em Diferença e repetição. Há uma mudança de termos no modo de conceber essa instância não-representativa da experiência, não mais tão atrelada ao contexto do estruturalismo ou mesmo da psicanálise. Como observa Monique DavidMénard em seu Deleuze e a psicanálise: "Os devires desafiam todas as classificações por gêneros, sejam os gêneros do Ser, as espécies biológicas ou os gêneros sexuais" 30 . Os devires prolongam aquela experiência da diferença como elemento individuante e impessoal, quando já não postulamos um sujeito transcendental com suas representações como dado e pressuposto.

\footnotetext{
${ }^{27}$ DELEUZE E GUATTARI, Mil platôs vol. 3, p. 41.

${ }^{28}$ DELEUZE E GUATTARI, Mil platôs vol. 3, p. 41.

${ }^{29}$ DELEUZE E GUATTARI, Mil platôs vol. 3, p. 53.

${ }^{30}$ DAVID-MÉNARD, Deleuze e a psicanálise, p. 121.
} 
Mas o que é o rosto senão uma conjugação de linhas e pontos sob uma superfície? Linhas essas que atadas aos significantes (Deus, Pai, Homem) produzem as representações como máscaras identitárias contenedoras de desvianças. Desfazer o rosto, desfazer a ordem imitativa de uma pintura, ou mesmo desfazer o corpo organizado constituem no ato de liberar linhas de suas fixações em pontos estabelecidos; uma abertura ao devir, seguir uma "linha de fuga". Os devires se dão quando essas linhas não conformadas prolongam seus traçados por direções insuspeitas, mas ao invés de seguirem apenas um "desvio da norma" começam a ganhar uma consistência, como em um esboço ou um "plano de criação" - ainda que seja preciso muita "prudência [...] para que o plano de consistência não devenha um puro plano de abolição, ou de morte"31.

Devir é instaurar uma outra relação - "molecular", conforme Deleuze e Guattari com os elementos diferenciais de nossa experiência (planta, animal ou molécula) que não se dá por imitação. É um "processo do desejo" 32 que nos põe em contato com a "mulher molecular", com o animal, com a criança, disparatantes em relação aos "sujeitos molares que conhecemos fora de nós, e que reconhecemos à força de experiência, de ciência ou de hábito" ${ }^{33}$. A crítica da representação, em suas implicações metafísicas, estéticas e políticas ao encontrar no conceito de "devir" uma instância molecular das diferenças puras - descobre uma radicalidade pouco explorada do caráter experimental do pensamento. Descobre um movimento que vai de um "devir mulher-molecular", como o primeiro "segmento" em confronto com o "homem molar", ao "fim imanente do devir" 34 ou "devir imperceptível": ao mesmo tempo imperceptível, indiscernível, impessoal.

Era justamente isso que a representação bloqueava em Diferença e repetição: o “insensível, o que não pode ser sentido, porque está sempre recoberta por uma qualidade que a aliena ou que a 'contraria', distribuída num extenso que a subverte e anula" 35 . O problema de todo experimentalismo, o de alcançar "estados alterados de percepção", quando o movimento dos devires se liberta das mediações que conformavam sua experiência perceptiva (excesso de percepção), encontra no "devir-imperceptível" uma arte dos "planos" que alcança "o imperceptível enfim percebido, o clandestino que nada mais tem a esconder" ${ }^{36}$. Mudar a percepção é um modo de "devir todo mundo" ${ }^{37}$ que é muito diferente de uma identificação com um ícone que "me representa" seja enquanto sujeito ou grupelho; implica encontrar uma "zona de indiscernibilidade" com o próprio mundo e as múltiplas formas de povoá-lo.

\footnotetext{
${ }^{31}$ DELEUZE E GUATTARI, Mil Platôs vol. 4, p. 63.

32 DELEUZE E GUATTARI, Mil Platôs vol. 4, p. 67.

33 DELEUZE E GUATTARI, Mil Platôs vol. 4, p. 71.

${ }^{34}$ DELEUZE E GUATTARI, Mil Platôs vol. 4, p. 76.

35 DELEUZE, Diferença e repetição, p. 333.

36 DELEUZE E GUATTARI, Mil Platôs vol. 4, p. 91.

${ }^{37}$ DELEUZE E GUATTARI, Mil Platôs vol. 4, p. 77.
} 


\section{AESTHETHICS AND POLITICS VARIATIONS CONCERNING TO THE NON- REPRESENTATIVE THINK}

Abstract: The representations don't exhausts the events, but restrict us to defined modes of see, feel and enunciate, that are closed perspectives of ours aesthetics and politics experiences. In front of this, is it possible to think beyond representations? From discuss this question, our paper proposes one reading of Friedrich Nietzsche, Gilles Deleuze, Michel Foucault and Jacques Rancière concerning to the critic of the representative paradigm, focused on Deleuze's solo works and together with Félix Guattari, when they discuss the concept of faciality. First, we'll talk about the most important event to human existence, according to Nietzsche: the death of God. This implies one rupture in traditional modes of think with the morals and metaphysics representations of existence. In this way, the death of God will be the sense horizon for one mode of thinking in Deleuze and Foucault that considerate the things and the representations attributing to they, like an interpretation of a subjectivation process in a field of forces in conflict. Lastly, based on the Rancièrian's concept of the distribution of sensible, we can avaliates the other way at which Deleuze proposes other distribution of the sensible and politics.

Keywords: event - faciality - aesthetics modernity - subjectivity.

\section{REFERÊNCIAS BIBLIOGRÁFICAS}

DAVID-MÉNARD, Monique. Deleure e a psicanálise. Rio de Janeiro: Civilização Brasileira, 2014.

DELEUZE, Gilles. Diferença e repetição. Rio de Janeiro: Graal, 2009.

Francis Bacon: Logique de la sensation. Paris: Ed. de la Différence, 1981.

Lógica do sentido. São Paulo: Perspectiva, 2007.

DELEUZE, Gilles; GUATTARI, Félix. Mil Platôs, vol. 3. Rio de Janeiro: Editora 34, 2012.

. Mil Platôs, vol. 4. Rio de Janeiro: Editora 34, 2012.

FOUCAULT, Michel. As palavras e as coisas. São Paulo: Martins Fontes, 1999.

NIETZSCHE, Friedrich. A gaia ciência. São Paulo: Companhia das Letras, 2007.

RANCIÈRE, Jacques. A partilha do sensivel. São Paulo: Editora 34, 2009.

"Existe uma estética deleuziana?”. In: Gilles Delenz̨e: uma vida filosófica. São Paulo: Editora 34, 2000. 